\title{
Ectopic Acromegaly Arising from a Pituitary Adenoma within the Bony Intersphenoid Septum of a Patient with Empty Sella Syndrome
}

\author{
Audrey E. Arzamendi ${ }^{1} \quad$ Kiarash Shahlaie $^{2} \quad$ Richard E. Latchaw $^{3} \quad$ Mirna Lechpammer $^{4}$ \\ Hasmik Arzumanyan ${ }^{1}$
}

${ }^{1}$ Division of Endocrinology, Diabetes \& Metabolism, Department of Internal Medicine, UC Davis Medical Center, Sacramento, California, United States

2 Department of Neurological Surgery, UC Davis Medical Center, Sacramento, California, United States

${ }^{3}$ Department of Radiology, UC Davis Medical Center, Sacramento, California, United States

${ }^{4}$ Department of Pathology, UC Davis Medical Center, Sacramento, California, United States

\author{
Address for correspondence Hasmik Arzumanyan, MD, Division of \\ Endocrinology, Diabetes \& Metabolism, Department of Internal \\ Medicine, UC Davis Medical Center, Kaiser Permanente Oakland, 3505 \\ Broadway, Suite 571, Oakland, CA 94611, United States \\ (e-mail: hasmik.arzumanyan@kp.org).
}

J Neurol Surg Rep 2016;77:e113-e117.

\begin{abstract}
Keywords

- acromegaly

- empty sella syndrome

- pituitary adenoma

- sphenoid sinus septum

Objective To describe the work-up and treatment of rare ectopic acromegaly caused by a biopsy-proven somatotroph pituitary adenoma located within the bony intersphenoid septum of a patient with empty sella syndrome (ESS).

Methods We report the presentation, clinical course, diagnostic work-up, and lesion localization and treatment challenges encountered in a 55-year-old patient, with a brief review of relevant literature.

Results A 55-year-old African-American man presented with acromegaly and ESS. Attempts to definitively localize the causative tumor were unsuccessful, though petrosal sinus sampling supported central growth hormone production and imaging suggested bone-enclosed subsellar pituitary tissue. Endoscopic endonasal transphenoidal exploration was undertaken with resection of a somatotroph pituitary microadenoma, and subsequent clinical improvement and biochemical remission. Retrospective review revealed the patient's pituitary to have been located ectopically within a unique bony intersphenoid septum.

Conclusion This report describes the first known case of an ectopic pituitary adenoma located within the midline bony intersphenoid septum, which we postulate to have resulted from anomalous embryological pituitary migration. Intra-intersphenoid septal tumors should be considered in cases of apparent central acromegaly with ESS or absence of tumor tissue within the paranasal sinuses or other peripheral locations. Indexing Acromegaly, ESS, pituitary adenoma, sphenoid sinus septum.
\end{abstract}

received

August 29, 2015 accepted after revision May 30, 2016
DOI http://dx.doi.org/ 10.1055/s-0036-1585091. ISSN 2193-6358. (c) 2016 Georg Thieme Verlag KG Stuttgart · New York
License terms

(c) (i) $\ominus$ (\$) 


\section{Background}

Empty sella syndrome (ESS) describes a cerebrospinal-fluidfilled sella turcica associated with a shrunken and/or flattened pituitary gland. Pituitary function is generally preserved, though hyperprolactinemia or partial-to-total hypopituitarism occurs in approximately $50 \%$ of patients. ${ }^{1-3}$ The most prevalent hormone deficiency in this syndrome is growth hormone $(\mathrm{GH})$ deficiency, affecting 35 to $61 \%$ of adult patients with ESS. ${ }^{4-6}$ Pituitary hyperfunction only rarely occurs in ESS, and acromegaly is perhaps the least common manifestation in this setting. ${ }^{7-9}$

While autoremission of acromegaly after pituitary infarction or hemorrhage has been described, it is uncommon for an acromegaly-causative pituitary adenoma to evade visualization on pituitary magnetic resonance imaging (MRI), much less for an empty sella (ES) alone to be present. ${ }^{10,11}$ In cases where only an ES is visualized, ectopic acromegaly should be considered, though it is responsible for less than $1 \%$ of cases. The vast majority of ectopic acromegaly results from neuroendocrine GH releasing hormone (GHRH)-secreting tumors, but isolated reports have described ectopic acromegaly from GH-secreting pancreatic islet-cell or lymphoma neoplasms, ${ }^{12,13}$ and 14 cases have been ascribed to abnormally located pituitary tissue. ${ }^{14}$

This case describes the work-up and treatment of a phenomenon not previously documented-rare ectopic acromegaly caused by a biopsy-proven somatotroph pituitary adenoma located within the bony intersphenoid septum of a patient with baseline ESS.

\section{Clinical Case}

A 55-year-old African-American man presented with a history of having grown "bigger" in his late thirties, with particular hand, foot, and hat size enlargement of the prior 3 years. He reported fatigue, arthralgias, oily skin, and decreased libido. He denied a family history of endocrine disorders. Physical examination was notable for a blood pressure of $151 / 83 \mathrm{~mm} \mathrm{Hg}$, rate-controlled atrial fibrillation, weight $=147 \mathrm{~kg}$, height $=6^{\prime} 7 "$, and body mass index $=37$. The patient appeared to be acromegalic, with frontal bossing, coarse facial features, enlarged nose, macrognathia, macroglossia, and widened interdental spaces. His hands and feet were enlarged and he exhibited pedal edema.

Laboratory tests confirmed acromegaly, with a serum insulinlike growth factor 1 (IGF-1) level of $560 \mathrm{ng} / \mathrm{mL}$ (81-225 ng/mL) and GH level of $16.7 \mathrm{ng} / \mathrm{mL}(0.05-3.00$ $\mathrm{ng} / \mathrm{mL}$ ). Pituitary MRI showed an enlarged ES with subtle left anterolateral pituitary tissue but no distinct intrasellar adenoma; however, a sphenoid sinus mass extending from the infundibulum was also visualized, projecting inferiorly from the sellar floor ( - Fig. 1). This seemed suggestive of a bone-enclosed ectopic pituitary tumor; however, further confirmatory work-up was felt indicated as such a tumor had not previously been described.

Pan-computed tomography (CT) with contrast demonstrated gross cardiomegaly but was otherwise negative for concerning masses. ${ }^{1,11}$ In-labeled octreotide scintigraphy was also unremarkable, and further work-up to rule out

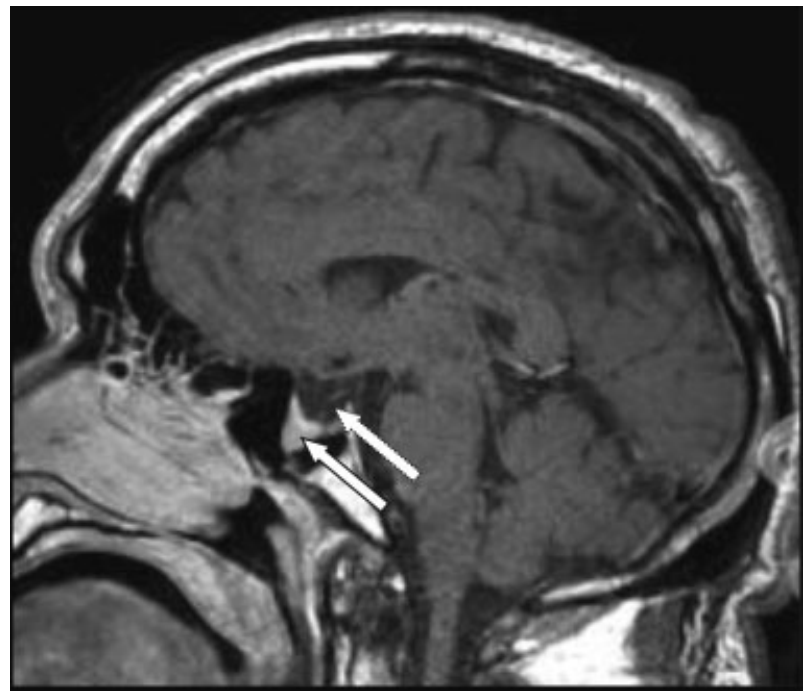

Fig. 1 Initial magnetic resonance imaging scan of the head. Sagittal enhanced spin echo T1 thin section through the sella shows a mass in the sphenoid sinus (solid arrow) in continuity with the infundibulum, and an empty sella (dotted arrow) with tissue along its floor.

possible GH hypersecretion was not immediately pursued as per the patient's request. The patient was treated briefly with octreotide, but self-discontinued this due to visual hallucinations and declined further medical or surgical therapy.

The patient was lost to follow-up for over a year. Repeat laboratory tests showed persistent acromegaly (GH: $6.37 \mathrm{ng} / \mathrm{mL}$; IGF-1: $771 \mathrm{ng} / \mathrm{mL}$ ), and a $75-\mathrm{g}$ oral glucose tolerance test failed to suppress $\mathrm{GH}$. Other pituitary-axis hormones including prolactin $(10.4 \mathrm{ng} / \mathrm{mL}$; reference: 2.1-17.7 ng/mL) remained normal. Brain CT again did not recognize distinct tumor, but demonstrated stable ES configuration and unknown subsellar tissue within the bony intersphenoid septum (-Fig. 2). A low-normal GHRH level of $7 \mathrm{pg} / \mathrm{mL}$ (5-18 pg/mL) ruled out an ectopic neuroendocrine tumor, and repeated. ${ }^{1,11}$ In-labeled octreotide scintigraphy was negative. The patient continued to decline surgery and therefore was resumed on octreotide, but he again discontinued this due to side effects.

He was hospitalized several months later for obstructive gastrointestinal symptoms. IGF-1 level was unexpectedly normal at $92 \mathrm{ng} / \mathrm{mL}$ (confirmed on recheck 1 week later with IGF-1 level of $174 \mathrm{ng} / \mathrm{mL}$ ); IGF-binding protein-3 was elevated at $6,430 \mathrm{ng} / \mathrm{mL}(2,592-4,770 \mathrm{ng} / \mathrm{mL})$, ruling out elevated free IGF-1. Pituitary MRI again revealed an ES without evidence of hemorrhage or infarction, and stable tissue-filled bony projection from the sellar floor extending into the medial aspect of the sphenoid sinus (-Fig. 3). Given the patient's normalized IGF-1 and absence of distinct intrasellar pituitary adenoma on imaging, spontaneous remission of acromegaly was considered; however, 75-g oral glucose tolerance testing failed to suppress GH. Petrosal sinus sampling showed an approximately six- to sevenfold central-toperipheral GH gradient (peripheral $=3.27$; left $=17.80$; right $=20.20$ ), consistent with central GH production. 

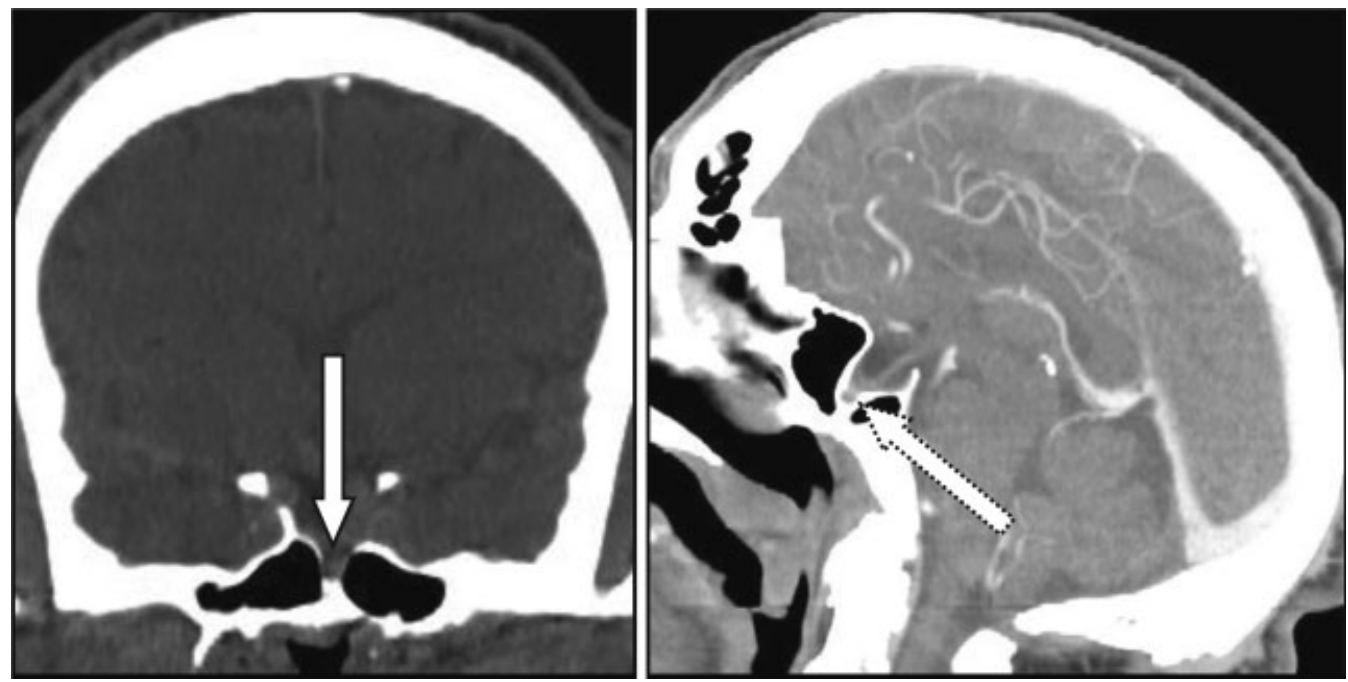

Fig. 2 Coronal and sagittal computed tomography (CT) head. Left: Coronal enhanced CT scanning through the midsella using a bone window demonstrates the widened intersphenoid septum containing ectopic pituitary tissue (solid arrow). Right: Sagittal enhanced CT shows a sellar floor defect, enhancing pituitary tissue within the intersphenoid septum (dotted arrow) and marginally lining the sellar floor.

A direct endoscopic endonasal transsphenoidal approach was used to explore the sella turcica. A midline sphenoid sinus septa was resected, and the anterior wall and floor of the sella turcica were removed. The dura overlying the pituitary gland extended into an expansion of the sphenoid sinus; this dura was resected, revealing underlying soft tumor tissue that was removed using ring curettage and suctioning. Posterior to this tissue, normal pituitary gland tissue was identified.

Histology confirmed a typical pituitary adenoma, with cells that were positive for both human GH and prolactin by immunohistochemistry (-Fig. 4). Twenty-four hours after surgery, GH level was normal at $1.65 \mathrm{ng} / \mathrm{mL}(0.05-3.00 \mathrm{ng} / \mathrm{mL})$, and other pituitary hormones remained within normal limits. Follow-up IGF-1 level 2 months after surgery was $67 \mathrm{ng} / \mathrm{mL}$.

\section{Discussion}

Acromegaly stems from GH-secreting pituitary tumors in approximately $99 \%$ of all cases, and most tumors are visible on MRI of the sella. ${ }^{10}$ Only six prior instances of acromegaly occurring with both radiographic ESS and an ectopic sphenoid sinus pituitary adenoma have been documented. ${ }^{14-19}$ While our patient's pituitary location within the walls of the bony intersphenoid septum was suggested by CT and MRI studies, it appears to be a unique anatomical variation not previously described. It was recognized as pituitary tissue only retrospectively, on collaborative interdepartmental review of intraoperative findings and imaging, highlighting the difficulty of intrabony adenoma identification. Since pituitary remnants
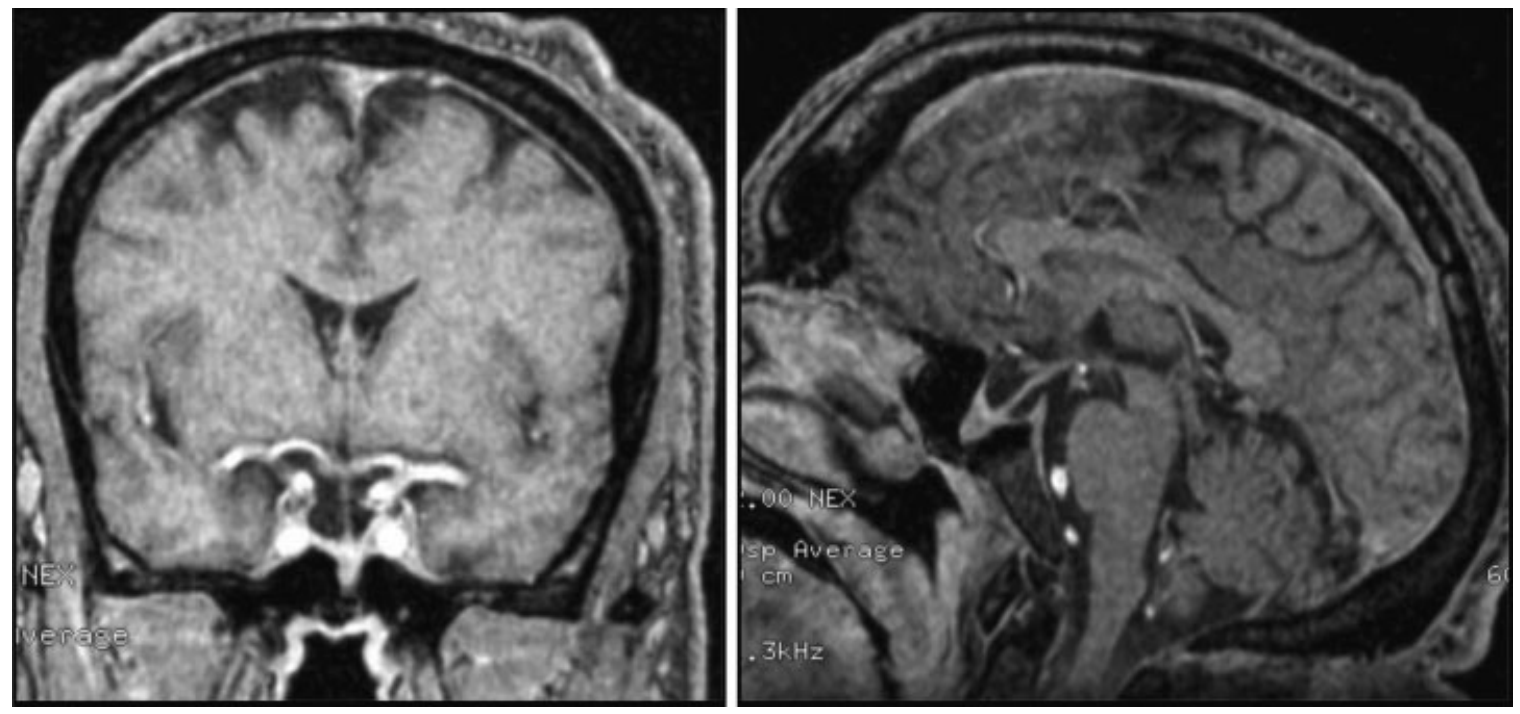

Fig. 3 Coronal (left) and sagittal (right) magnetic resonance imaging head scans. Enhanced fat-suppressed spin echo T1 images through the midsella demonstrate a stable mass in continuity with the infundibulum, extending below the sellar floor and into the widened intersphenoid septum. 


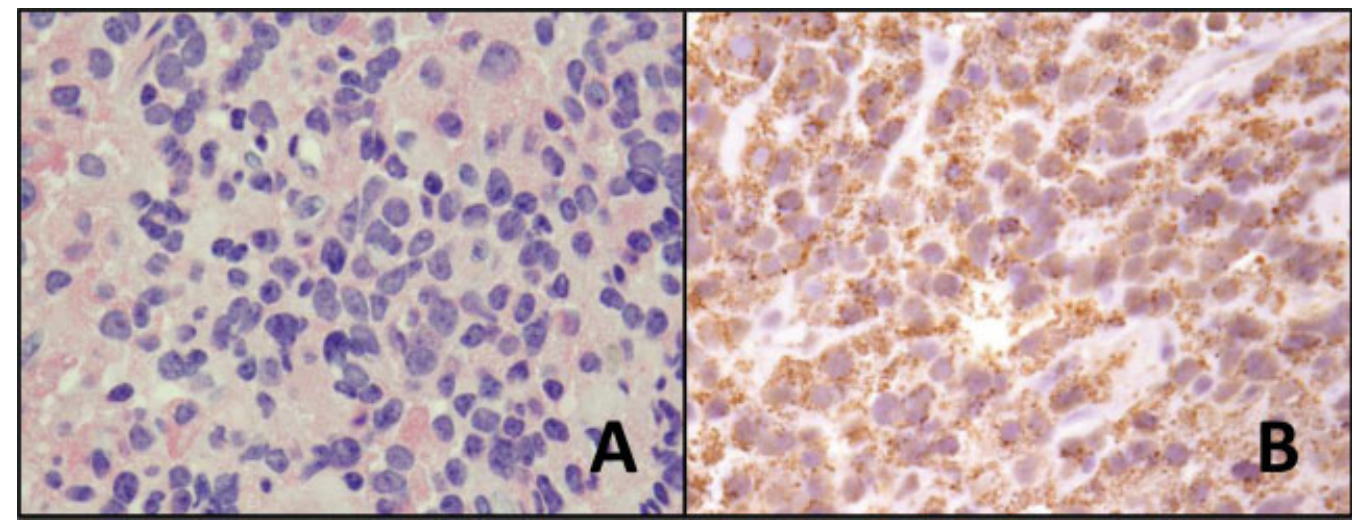

Fig. 4 Pituitary adenoma with growth hormone $(\mathrm{GH})$ secretion. Formalin-fixed, paraffin-embedded tissue histology demonstrates pituitary adenoma (A: 1,000× magnification; hematoxylin-eosin stain) and $\mathrm{GH}$ secretion (B: 1,000× magnification; polyclonal rabbit antihuman $\mathrm{GH}$ antibody). Tissue also stained positive for prolactin (not shown).

laying outside the hypophyseal portal system may be less susceptible to normal hypothalamic regulation, ${ }^{20}$ it is possible that other cases of intrabony adenomas within the intersphenoid septum have gone unrecognized in patients with pituitary hormone dysregulation and ESS/unidentified tumor.

It is unclear how this patient's pituitary anomaly developed. Ectopic pituitary tissue is most often situated in the sphenoid sinus or nasopharynx ${ }^{14}$ and is felt to result from faulty embryological migration and invagination course of Rathke's pouch, or mechanical adenoma protrusion through sellar floor defects (especially in conjunction with higher fluid-filled ES/intracranial pressure). ${ }^{19,21}$ Absent, eroded, and intact sellar floors were all described in six previously documented cases of acromegaly with combined ESS and sphenoid sinus ectopic adenoma ${ }^{14}$; our patient demonstrated an absent sellar floor. His enlarged sella and absent sellar floor might support a mechanical eventperhaps an originally larger macroadenoma which then hemorrhaged, necrosed, and involuted. Intracranial hypertension might then have led to an expanded sella along with caudal descent/flattening of the pituitary and extension into the intersphenoid septum, where the remaining tumor ultimately settled. Secondary ESS (and often, associated acromegaly remission) has been a documented sequela to pituitary apoplexy ${ }^{22-27}$; however, increased intracranial pressure or aggressive tumor growth would theoretically displace the pituitary lateral to the intersphenoid septum along the path of least resistance, rather than induce a "split" configuration in the existing septal bone. Furthermore, our patient's earliest baseline MRI suggested primary ESS with no evidence of hemorrhagic or apoplectic evolution over several years of follow-up imaging, and while his IGF-1 levels decreased 5 years into his course, repeat oral glucose tolerance testing confirmed persistent biochemical acromegaly. Therefore, we postulate that our patient's clinical course and split bony septum (with smooth walls surrounding the ectopic pituitary) best support an anomalous embryological migration etiology, with baseline sellar floor incompetence also enabling his ultimate pituitary ectopy.

Treatment of patients with acromegaly and nonvisualized and/or extrasellar-sellar tumors poses a challenge to definitive acromegaly management, which generally demands source localization followed by surgical tumor resection. To our knowledge, octreotide scintigraphy has been utilized in only one prior case of ectopic pituitary acromegaly, and that scan successfully identified the sphenoid sinus adenoma. ${ }^{14}$ However, our patient's scan was unremarkable, failing to reveal his intersphenoid septum tissue as an acromegalycausative tumor.

Ultimately, our patient was successfully treated with transsphenoidal resection. His ectopic pituitary was demonstrated on serial CTs/MRIs, but was confirmed only retrospectively as pituitary tissue, due to lack of previously reported bony-encased intrasphenoid septal tumors and unfamiliarity with this diagnosis. Therefore, in his case, repeated testing and imaging were necessary to rule out a nonpituitary etiology and to better predict a central pathology amenable to neurosurgical resection. In this patient, a low GHRH ruled out an ectopic GHRH-secreting neuroendocrine tumor; and repeat. ${ }^{1,11}$ In-labeled octreotide scintigraphy, pan-CT, and petrosal sinus sampling ruled out a noncentral location.

Although our patient's tumor location within a bony septum is unique, its location in the sphenoid sinus was consistent with other extrasellar reports-12 of the 14 previously reported cases of "ectopic adenoma acromegaly" involved tumors within the sphenoid sinus. ${ }^{14}$ Our article demonstrates that in cases of central acromegaly, where imaging shows ESS and fails to identify an adenoma in paranasal sinuses or other peripheral locations, it is prudent to review MRI scans for a possible intra-intersphenoid septal tumor.

\section{Disclosure}

The authors have no multiplicity of interest to disclose.

\section{References}

1 Buchfelder M, Brockmeier S, Pichl J, Schrell U, Fahlbusch R. Results of dynamic endocrine testing of hypothalamic pituitary function in patients with a primary "empty" sella syndrome. Horm Metab Res 1989;21(10):573-576 
2 Santeusanio F. Hand primary empty sella. J Endocrinol Invest. 2002;25(7):574-575

3 Ghatnatti V, Sarma D, Saikia U. Empty sella syndrome - beyond being an incidental finding. Indian J Endocrinol Metab 2012;16 (Suppl 2):S321-S323

4 Del Monte P, Foppiani L, Cafferata C, Marugo A, Bernasconi D. Primary "empty sella" in adults: endocrine findings. Endocr J 2006;53(6):803-809

5 Cannavò S, Curtò L, Venturino M, et al. Abnormalities of hypothalamic-pituitary-thyroid axis in patients with primary empty sella. J Endocrinol Invest 2002;25(3):236-239

6 Gasperi M, Aimaretti G, Cecconi E, et al. Impairment of $\mathrm{GH}$ secretion in adults with primary empty sella. J Endocrinol Invest 2002;25(4):329-333

7 Coulson CJ, Siddiq MA, Johnson AP. Empty sella syndrome associated with a hyperfunctioning microadenoma invading the clivus. Br J Neurosurg 2007;21(6):623-625

8 Hekimsoy Z, Yünten N, Sivrioglu S. Coexisting acromegaly and primary empty sella syndrome. Neuroendocrinol Lett 2004;25(4): 307-309

9 Molitch ME, Hieshima GB, Marcovitz S, Jackson IM, Wolpert S. Coexisting primary empty sella syndrome and acromegally. Clin Endocrinol (Oxf) 1977;7(3):261-263

10 Khandelwal D, Khadgawat R, Mukund A, Suri A. Acromegaly with no pituitary adenoma and no evidence of ectopic source. Indian J Endocrinol Metab 2011;15(Suppl 3):S250-S252

11 Fibbi B, Maggioli C, Vannucci L, et al. A case of acromegaly without clear evidence of pituitary adenoma or ectopic GH/GHRH secreting tumors. Endocrine Abstracts 2012;29:349

12 Melmed S, Ezrin C, Kovacs K, Goodman RS, Frohman LA. Acromegaly due to secretion of growth hormone by an ectopic pancreatic islet-cell tumor. N Engl J Med 1985;312(1):9-17

13 Beuschlein F, Strasburger CJ, Siegerstetter V, et al. Acromegaly caused by secretion of growth hormone by a non-Hodgkin's lymphoma. N Engl J Med 2000;342(25):1871-1876

14 Ramírez C, Hernández-Ramirez L-C, Espinosa-de-los-Monteros AL, Franco JM, Guinto G, Mercado M. Ectopic acromegaly due to a GH-secreting pituitary adenoma in the sphenoid sinus: a case report and review of the literature. BMC Res Notes 2013;6:411

15 Matsuno A, Katayama H, Okazaki R, et al. Ectopic pituitary adenoma in the sphenoid sinus causing acromegaly associated with empty sella. ANZ J Surg 2001;71(8):495-498
16 Hori E, Akai T, Kurimoto M, Hirashima Y, Endo S. Growth hormone-secreting pituitary adenoma confined to the sphenoid sinus associated with a normal-sized empty sella. J Clin Neurosci 2002; 9(2):196-199

17 Gondim JA, Schops M, Ferreira E, Bulcão T, Mota JI, Silveira C. Acromegaly due to an ectopic pituitary adenoma in the sphenoid sinus. Acta Radiol 2004;45(6):689-691

18 Kurowska M, Tarach JS, Zgliczyński W, Malicka J, Zieliński G, Janczarek M. Acromegaly in a patient with normal pituitary gland and somatotropic adenoma located in the sphenoid sinus. Endokrynol Pol 2008;59(4):348-351

19 Appel JG, Bergsneider M, Vinters H, Salamon N, Wang MB, Heaney AP. Acromegaly due to an ectopic pituitary adenoma in the clivus: case report and review of literature. Pituitary 2012;15(Suppl 1): S53-S56

20 Bhatoe HS, Kotwal N, Badwal S. Clival pituitary adenoma with acromegaly: case report and review of literature. Skull Base 2007; 17(4):265-268

21 Hong JF, Ding XH, Wang SS. Coexistence of ectopic pituitary adenoma and empty sella in a patient with acromegaly: a case report and review of literature. Neurol India 2012;60(3): 304-306

22 Wang XL, Dou JT, Lü ZH, et al. Spontaneous remission of acromegaly or gigantism due to subclinical apoplexy of pituitary growth hormone adenoma. Chin Med J (Engl) 2011; 124(22):3820-3823

23 Imaki T, Yamada S, Harada S, Tsuchiya M, Sano T, Demura H. Amelioration of acromegaly after pituitary infarction due to gastrointestinal hemorrhage from gastric ulcer. Endocr J 1999; 46(1):147-151

24 Thomas N, Simon R, Chacko G, Chacko AG, Chandy MJ, Seshadri MS. Regression of acromegaly following pituitary apoplexy. Neurol India 1999;47(2):161-162

25 Kato K, Nobori M, Miyauchi Y, et al. Pituitary apoplexy after subtotal thyroidectomy in an acromegalic patient with a large goiter. Intern Med 1996;35(6):472-477

26 Abe K, Hirata Y. A case of acromegaly improved by pituitary apoplexy. Endocrinol Jpn 1975;22(2):181-186

27 Nishioka H, Haraoka J, Miki T. Spontaneous remission of functioning pituitary adenomas without hypopituitarism following infarctive apoplexy: two case reports. Endocr J 2005;52(1): $117-123$ 